\title{
Intraabdominal gossypiboma: Report of two cases
}

\author{
Ebru Oran, Gürkan Yetkin, Nurcihan Aygün, Fevzi Celayir, Mehmet Uludağ
}

$\begin{array}{ll}\text { ABSTRACT } & \text { Gossypiboma which cause medico-legal implications is a heritage of previous surgery. In this study, we present } \\ \text { two cases of gossypiboma mimicking intraabdominal malignancy. Case 1: A 28-year-old woman presented with an } \\ \text { epigastric mass measuring } 10 \mathrm{~cm} \text { in diameter and a history of open cholecystectomy performed three years ago. } \\ \text { Radiological exams revealed a cystic mass at the lesser sac and suggested serous cystadenocarcinoma. Case 2: A } \\ \text { 36-year-old female patient with a history of two caesarean sections had a mass in the left lower quadrant. Radio- } \\ \text { logical imaging showed tumoral mass near the left ovary. The exact diagnosis of gossypiboma were achieved by } \\ \text { laparotomy and pathological examination in both cases. Gossypibomas usually present with nonspecific symptoms } \\ \text { and appear many years after surgery. Therefore, its preoperative diagnosis is very difficult. High degree of suspicion } \\ \text { is essential and it should be considered in the differential diagnosis of intraabdominal masses in patients who have } \\ \text { previously undergone surgery. } \\ \text { Keywords: Intraabdominal mass, foreign body, gossypiboma }\end{array}$

Cite this paper as: Oran E, Yetkin G, Aygün $\mathrm{N}$, Celayir F, Uludağ M. Intraabdominal gossypiboma: Report of two cases. Turk J Surg 2018; 34: 77-79.

Department of General Surgery, Şişli Etfal Training and Research Hospital, İstanbul, Turkey

Address for Correspondence
Ebru Oran
e-mail: ebrusenoran@windowslive.
com
Received: 23.03 .2015
Accepted: 07.05 .2015
OCopyright 2018
by Turkish Surgical Association
Available online at
www.turkjsurg.com

\section{INTRODUCTION}

Gossypiboma or textiloma is used to describe a retained surgical sponge as a heritage of previous surgery, causing medico-legal issues. General surgical operations (52\%) and gynecologic procedures (22\%) are the main interventions related to gossypiboma (1). Although they may be detected in various parts of the body, gossypibomas are mostly found in the abdomen (56\%), pelvis (18\%), and thorax (11\%) according to the study by Wan et al. (2). Its reported frequency varies between 1 out of 1,000 and 1 out of 1,500 intraabdominal operations, whereas actual occurrence rate is believed to be much higher (3).

Gossypiboma may appear either immediately or as long as a few decades after an operation and its symptoms are usually nonspecific. Thus, diagnosis tends to be difficult and usually is established with operation. Here, we present two cases of gossypiboma mimicking an intraabdominal malignancy.

\section{CASE PRESENTATIONS}

\section{Case 1}

A 28-year-old woman presented with a history of open cholecystectomy performed three years ago and was admitted to our clinic. She was suffering from abdominal pain and on physical examination, a mass lesion was found at the epigastric region. Biochemical parameters were normal. Abdominal computed tomography $(\mathrm{CT})$ with intravenous contrast revealed a well-defined heterogeneous mass with a dense, enhanced wall, measuring $77 \times 65 \times 108 \mathrm{~mm}$ in diameter at the lesser sac with the contiguity of the left hepatic lobe, gastric antrum, and jejunal loops. Magnetic resonance imaging (MRI) was suggestive of serous cystadenocarcinoma of the pancreas. Gastroscopy was normal. After obtaining informed consent, laparotomy was performed; numerous dense adhesions between the lesion and the neighboring organs were observed and wall of the lesion was inadvertently opened during the dissection. Retained surgical sponges were detected from inside of the mass after running out of serous fluid. Mass was completely retrieved with pseudocapsule (Figure 1). Postoperatively, the patient recovered uneventfully. Microscopic examination revealed fibrous encapsulation containing the foreign-body giant cell reaction (Figure 2).

\section{Case 2}

A 36-year-old female patient was admitted to our clinic with the complaint of painful mass in the left lower quadrant for the last three months. There were two caesarean sections performed 13 and 15 years ago in her surgical background. A $10 \times 10-\mathrm{cm}$ mass was palpated on the left lower abdomen. Biochemical parameters were within normal limits. Ultrasonography showed a heterogeneous mass next to the left ovary and calcifications created acoustic shadows. On CT, a $110 \times 90 \times 70-\mathrm{mm}$ tumoral mass 
near the left ovary, with smooth borders and cystic, necrotic, and hyperdense foci in the center was observed (Figure 3). Informed consent was taken and in the exploratory laparotomy, the mass adherent to the posterior abdominal wall and surrounded by the omentum was encapsulated and resembled a stromal tumor. It was completely removed from neighboring structures including small bowel, left ovary, and fallopian tube (Figure 4). The patient was discharged on the postoperative 6th day. Pathological examination revealed the true nature of the lesion to be foreign-body-type granulation tissue.

\section{DISCUSSION}

Accidentally left surgical sponges present diverse clinical findings depending on the types of foreign body reactions in the

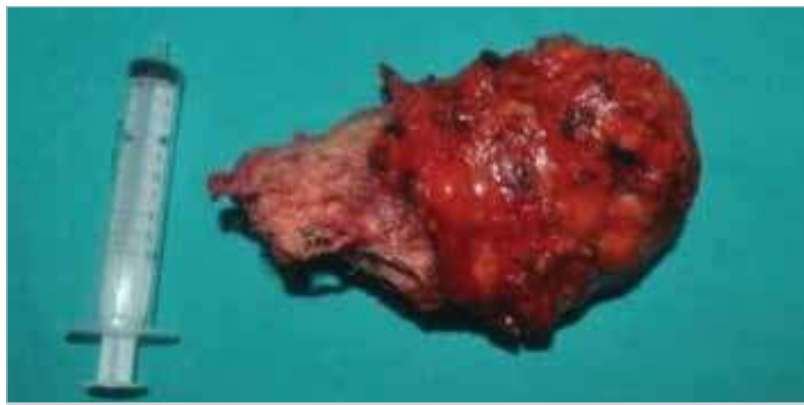

Figure 1. Mass was completely retrieved with pseudocapsule

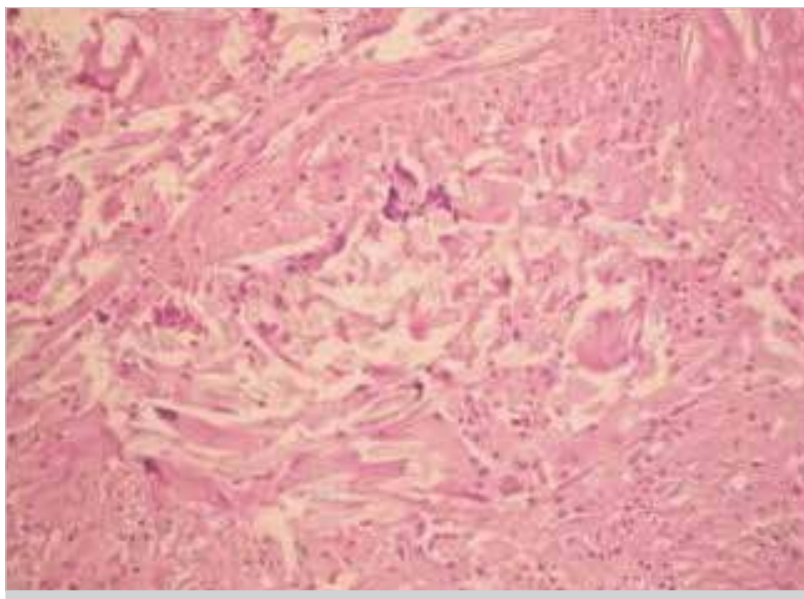

Figure 2. Pathological examination showed fibrous encapsulation containing the foreign-body giant cell reaction

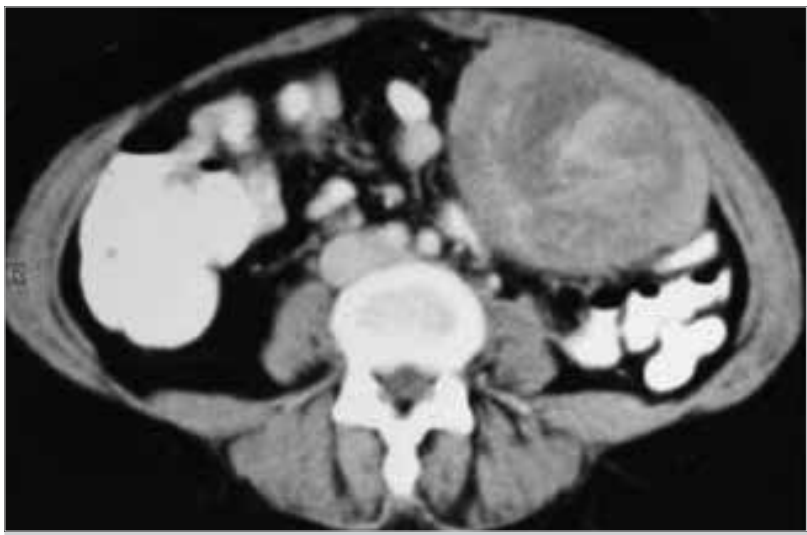

Figure 3. CT revealed a tumoral mass with smooth borders and cystic, necrotic and hyperdense foci in the center body and cause medico-legal issues. The first type of reaction is aseptic fibrinous reaction in which the adhesion and encapsulation results in a granuloma formation and remain asymptomatic for a long time (3-5). Then, similar to our cases, patients present with the symptoms of pseudotumor syndrome including abdominal pain, palpable mass, vomiting, diarrhea, abdominal distension, anorexia, and weight loss. Yildirim et al. (6) reported 14 patients with gossypiboma; 10 had aseptic fibrinous reactions, and the interval between first surgery and the onset of symptoms in their series varied between 12 months and 40 years. The second type of foreign body reaction is exudative inflammatory reaction, which usually is detected immediately following the surgery and by symptoms of the abscess or fistula formation (7). They may account for visceral perforation or obstruction by migrating into the luminal organs.

Gawande et al. (8) found that emergency interventions, unexpected changes in an operation, and high body mass index of the patient were the risk factors of leaving a foreign material inside the human body. Females have a greater possibility of this issue because of high number of gynecologic procedures, deep pelvis anatomy, and high body mass indexes (9). Similarly, our patients were female and obese, and one had two caesarean sections as a risk factor.

Preoperative correct diagnosis of gossypiboma has been reported to occur in only one-third of all cases (9). A new-onset or recurrent tumor is the most presumptive differential diagnosis of gossypiboma. This misdiagnosis may lead to extensive surgical resections and causes patient's anxiety as well. Therefore, gossypiboma should be included in the differential diagnosis of tumoral masses detected in patients with a history of a prior operation. In our first case, we suspected pancreatic serous cystadenocarcinoma in the light of radiological evaluations. The second case was suggested to be an intraabdominal stromal tumor. However, perioperative findings in the first case and the pathological examination in the second one revealed gossypiboma.

Although surgical sponges with radiopaque markers increase the probability of the detection of these retained swabs, the radiopaque filament is not always visible in a plain radiograph due to plication, bending, or fragmentation over time. Ultrasonographic finding of gossypiboma is a well-defined mass containing a wavy hyperechoic area and dense posterior acoustic

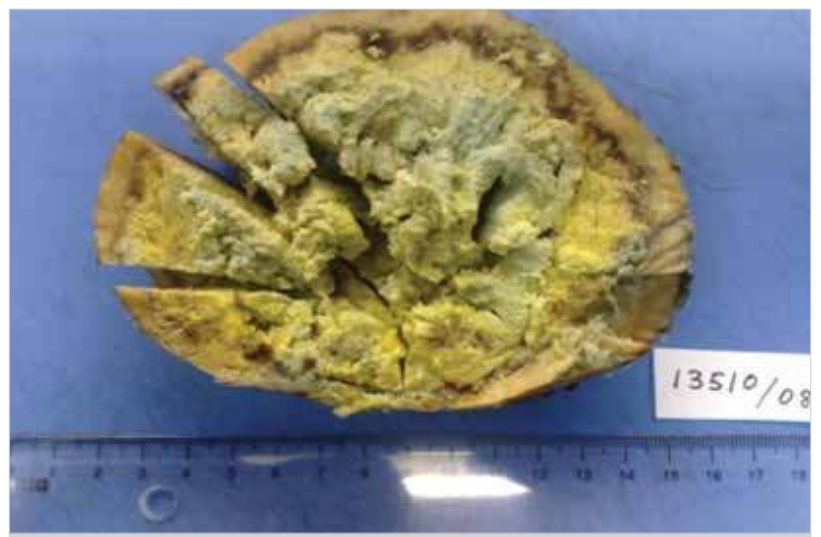

Figure 4. Macroscopic appearance of gossipiboma 
shadowing (5). On CT, it appears as a well-demarcated cystic lesion with hyperdense internal material showing spongiform air bubbles with marked rim enhancement and mural calcifications (10). MRI is also helpful by illustrating a mass with a center having variable signal intensity depending on the fluid and its protein content and peripheral wall enhancement after intravenous gadolinium administration on T1-weighted imaging (3).

Prevention of gossypiboma is more important than diagnosis and treatment. Therefore, only sponges with radiopaque markers should be used during laparotomy. Thorough count of surgical materials at the onset and the end of the procedure must be performed with patience. Exploration of the surgical field before the closure of the wound is essential. If there is any doubt regarding the count, the surgeons should carefully check the surgical sites and take abdominal x-rays. Adherence to these basic details and paying meticulous attention will decrease the incidence of gossypibomas, which also account for serious medico-legal problems.

\section{CONCLUSION}

Retained surgical sponges may cause granuloma with foreign body reactions and mimic malignancy. As gossypibomas usually present with nonspecific symptoms and appear many years after surgery, their preoperative diagnoses are very difficult and require high degree of suspicion. They should be considered in the differential diagnosis of intraabdominal masses in patients who have previously undergone abdominal surgery. Moreover, prevention of gossypiboma is crucial to avoid medico-legal issues.

Informed Consent: Written informed consent was obtained from patients who participated in this case.

Peer-review: Externally peer-reviewed.

Author Contributions: Concept - E.O., G.Y., M.U., F.C.; Design - E.O., F.C.; Supervision - E.O., F.C.; Data Collection and/or Processing - G.Y., N.A.;
Analysis and/or Interpretation - N.A., E.O., F.C.; Literature Search - E.O., N.A.; Writing Manuscript - E.O.; Critical Reviews - G.Y., M.U.

Conflict of Interest: No conflict of interest was declared by the authors.

Financial Disclosure: The authors declared that this study has received no financial support.

\section{REFERENCES}

1. Yamamura N, Nakajima K, Takahashi T, Uemura M, Nishitani A, Souma $Y$, et al. Intra-abdominal textiloma. A retained surgical sponge mimicking a gastric gastrointestinal stromal tumor: report of a case. Surg Today 2008; 38: 552-554. [CrossRef]

2. Wan W, Le T, Riskin L, Macario A. Improving safety in the operating room: $A$ systematic literature review of retained surgical sponges. Curr Opin Anaesthesiol 2009; 22: 207-214. [CrossRef]

3. Lata I, Kapoor D, Sahu S. Gossypiboma, a rare cause of acute abdomen: A case report and review of literature. Int J Crit IIIn Inj Sci 2011; 1: 157-160. [CrossRef]

4. Akbulut S, Sevinc MM, Basak F, Aksoy S, Cakabay B. Transmural migration of a surgical compress into the stomach after splenectomy: a case report. Cases J 2009; 2: 7975. [CrossRef]

5. Cheon JW, Kim EY, Kim KY, Park JB, Shin YK, Kim KY, et al. A case of gossypiboma masquerading as a gastrointestinal stromal tumor. Clin Endosc 2011; 44: 51-54. [CrossRef]

6. Yildirim S, Tarim A, Nursal TZ, Yildirim T, Caliskan K, Torer N, et al. Retained surgical sponge (gossypiboma) after intraabdominal or retroperitoneal surgery: 14 cases treated at a single center. Langenbecks Arch Surg 2006; 391: 390-395. [CrossRef]

7. Gencosmanoglu R, Inceoglu R. An unusual cause of small bowel obstruction: gossypiboma--case report. BMC Surg 2003; 3: 6. [CrossRef]

8. Gawande AA, Studdert DM, Orav EJ, Brennan TA, Zinner MJ. Risk factors for retained instruments and sponges after surgery. $\mathrm{N}$ Engl J Med 2003; 348: 229-235. [CrossRef]

9. Buluş H, Şımşek G, Coşkun A, Koyuncu A. Intraabdominal gossypiboma mimicking gastrointestinal stromal tumor: a case report. Turk J Gastroenterol 2011; 22: 534-536. [CrossRef]

10. Patil KK, Patil SK, Gorad KP, Panchal AH, Arora SS, Gautam RP. Intraluminal Migration of Surgical Sponge: Gossypiboma. Saudi J Gastroenterol 2010; 16: 221-222. [CrossRef] 